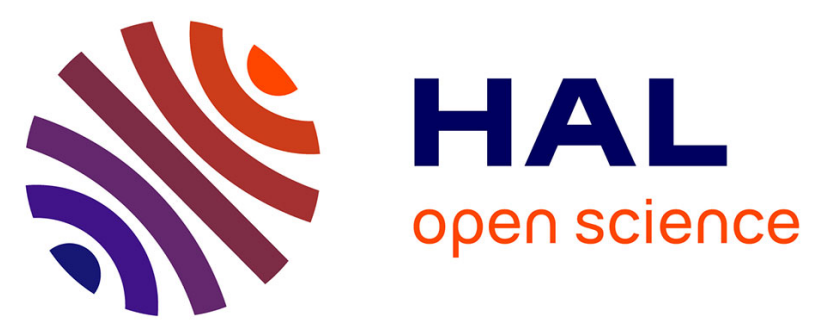

\title{
Pravastatin Reverses Established Radiation-Induced Cutaneous and Subcutaneous Fibrosis in Patients With Head and Neck Cancer: Results of the Biology-Driven Phase 2 Clinical Trial Pravacur
}

Céline Bourgier, Anne Auperin, Sofia Rivera, Pierre Boisselier, Benoit Petit, Philippe Lang, Nathalie Lassau, Patrice Taourel, Raphaël Tetreau, David Azria, et al.

\section{- To cite this version:}

Céline Bourgier, Anne Auperin, Sofia Rivera, Pierre Boisselier, Benoit Petit, et al.. Pravastatin Reverses Established Radiation-Induced Cutaneous and Subcutaneous Fibrosis in Patients With Head and Neck Cancer: Results of the Biology-Driven Phase 2 Clinical Trial Pravacur. International Journal of Radiation Oncology, Biology, Physics, 2019, 104 (2), pp.365-373. 10.1016/j.ijrobp.2019.02.024 . hal-02452478

\author{
HAL Id: hal-02452478 \\ https://hal.umontpellier.fr/hal-02452478
}

Submitted on 22 Oct 2021

HAL is a multi-disciplinary open access archive for the deposit and dissemination of scientific research documents, whether they are published or not. The documents may come from teaching and research institutions in France or abroad, or from public or private research centers.
L'archive ouverte pluridisciplinaire HAL, est destinée au dépôt et à la diffusion de documents scientifiques de niveau recherche, publiés ou non, émanant des établissements d'enseignement et de recherche français ou étrangers, des laboratoires publics ou privés.

\section{(ㄷ)(1) $\$$}

Distributed under a Creative Commons Attribution - NonCommerciall 4.0 International 


\section{PRAVASTATIN REVERSES ESTABLISHED RADIATION-INDUCED CUTANEOUS} AND SUBCUTANEOUS FIBROSIS IN PATIENTS WITH HEAD AND NECK CANCER: RESULTS OF THE BIOLOGY-DRIVEN PHASE II CLINICAL TRIAL PRAVACUR

CELINE BOURGIER, MD., PhD., ${ }^{1,2}$; ANNE AUPERIN, ${ }^{3}$; SOFIA RIVERA, MD., PhD., ; PIERRE BOISSELIER, MD., ${ }^{2}$; BENOIT PETIT, ${ }^{5}$; PHILIPPE LANG, MD., ${ }^{6}$; NATHALIE LASSAU, MD., PhD., ${ }^{7}$; PATRICE TAOUREL, MD., PhD., ${ }^{8}$; RAPHAEL TETREAU, MD., ${ }^{9}$; DAVID AZRIA, MD., PhD., ${ }^{1,2}$; JEAN BOURHIS, MD., PhD., 5; ERIC DEUTSCH, MD., PhD., ${ }^{4}$; MARIE-CATHERINE VOZENIN, PhD. ${ }^{5}$

${ }^{1}$ INSERM, U1194, IRCM, Univ Montpellier, Montpellier, France; ${ }^{2}$ Department of Radiation Oncology, ICM-Val d'Aurelle, Univ Montpellier, Montpellier, France ;

${ }^{3}$ Biostatistics Department, Gustave Roussy Institute, Villejuif, France ;

${ }^{4}$ INSERM 1030, Univ Paris-Sud, Department of Radiation Oncology, Gustave Roussy Cancer Campus, Villejuif, France, Univ Paris-Saclay ;

${ }^{5}$ Radiation Oncology Department, CHUV Lausanne, Switzerland ;

${ }^{6}$ Department of Radiation Oncology, CHU Nîmes, Univ Montpellier, Nîmes, France;

${ }^{7}$ Imaging Department, Gustave Roussy Institute, IR4M, Univ Paris Sud, Villejuif France ;

${ }^{8}$ Radiology Department, CHU Lapeyronie, Univ Montpellier, Montpellier, France ;

${ }^{9}$ Radiology Department, ICM-Val d'Aurelle, Univ Montpellier, Montpellier, France 
Correspondence to: Celine Bourgier, M.D., Ph.D., Department of Radiation Oncology, ICM-Val d'Aurelle, rue croix verte, 34298 Montpellier Cedex 5, France. Phone: +33 46761 31 32, Fax: +33 4676131 35, E-mail: celine.bourgier@icm.unicancer.fr

Running title: Statins mitigator radioinduced fibrosis

Funding: This work was supported by grants from the French National Hospital Clinical Research Program (PHRC) obtained in 2010

Disclosure: The authors declare no conflict of interest.

Acknowledgments: The authors would like to thank Elisabetta Andermarcher for English editing, Marc Bollet (Hartmann Hospital) and Xavier Cuenca (La Pitié Salpétrière Hospital) for referring patients with severe fibrosis.

Keywords: curative anti-fibrotic treatment, radio-induced fibrosis, statins

Oral communication: This work was selected for oral presentation at the 2017 ASTRO Annual Meeting and the 2018 ESTRO Annual Meeting.

Statistical analyses performed by Anne AUPERIN 


\section{ABSTRACT}

Purpose: The "xxx" phase II trial (NCTxxx) assessed the efficacy of pravastatin as antifibrotic agent in patients with established cutaneous and subcutaneous radiation-induced fibrosis (RIF) after head and neck squamous cell carcinoma (HNSCC) radiotherapy and/or radio-chemotherapy.

Methods and Materials: The main inclusion criteria were: patients with HNSCC in remission, with grade $\geq 2$ cutaneous and subcutaneous neck RIF (NCI-CTCAE v4.0); no current treatment with statins or fibrates. Patients received $40 \mathrm{mg}$ pravastatin/day for 12 months. The primary endpoint was reduction of RIF thickness by more than $30 \%$ at 12 months measured by cutaneous high-frequency ultrasonography (HF-US). Secondary endpoints included RIF severity reduction, pravastatin tolerance, and quality of life.

Results: 60 patients with grade $2(n=37)$, grade $3(n=22)$ or grade $4(n=1)$ RIF were enrolled from February 2011 to April 2016. The mean interval between RIF diagnosis and pravastatin initiation was 17.1 months. Pravastatin was stopped before 11 months of treatment in 18 patients [due to grade $\geq 2$ adverse events related to pravastatin in eight (13\%) patients]. Among the 40 patients in whom pravastatin efficacy was assessed by HF-US at baseline and at 12 months of treatment, a reduction of RIF thickness $\geq 30 \%$ was observed in 15 (35.7\% of $42,95 \%$ confidence interval (CI): $21.6 \%-52.0 \%$ ). At the 12-month clinical evaluation, RIF severity was decreased in 50\% of patients (21/42) (95\% CI: $34.2 \%-65.8 \%)$, and the patients' self-perception, mood state and social functioning were significantly improved. Pravastatin was well-tolerated with very low occurrence of grade 3 toxicities (myalgia, $n=1$ ) and grade 2 toxicities (myalgia/arthralgia or esophagitis, $n=3$ ).

Conclusions: This phase II prospective study supports the notion of radio-induced fibrosis reversibility. It showed that pravastatin (40mg/day for 12 months) is an efficient anti-fibrotic 
agent in patients with grade $\geq 2$ cutaneous and subcutaneous fibrosis after HNSCC radiotherapy. 


\section{INTRODUCTION}

Head and neck squamous cell carcinoma (HNSCC) can develop in four main locations: oral cavity, oropharynx, larynx and hypopharynx. In 2015, 932,614 new cases were reported worldwide, and HNSCC was the $7^{\text {th }}$ most common cancer and cause of death (1). The standard of care is a multimodal treatment approach with surgery followed by adjuvant radiotherapy (RT), or RT as definitive treatment. The control of locally advanced HNSCC, which is common in patients with history of smoking and alcohol consumption, has been significantly improved by the combination of RT and chemotherapy (RCT), and by RT altered fractionation. However, this population still displays poor outcome (2). Conversely, Human Papilloma Virus-positive and non-smoking related HNSCCs have a better prognosis (3).

Treatment intensification in HNSCC is associated with increased frequency and severity of radiation-induced toxicities, particularly radiation-induced fibrosis (RIF). Neck RIF is a substantial late toxicity. Indeed, at 3 years post-treatment, the risk of grade $\geq 2$ RIF is $56 \%$ and $28 \%$ in patients who received RT after or not neck surgery, respectively; and $34 \%$ after RCT alone (4). The use of modern RT modalities, such as intensity-modulated radiation therapy (IMRT), has significantly reduced the incidence of acute and late toxicities (5). However, grade $\geq 2$ RIF occurrence is still high even with IMRT. In a recent study, Nevens and colleagues observed grade $\geq 2$ RIF in $29.2 \%$ of patients at 6 months with an increased occurrence in the case of upfront neck dissection (70.6\% versus 18.1\%) (6). RIF functional consequences can lead to a decreased patients' quality of life (QoL) as well as to dysphagia, trismus, lymphedema and limited cervical range of motion (7).

RIF usually occurs at least 4 months after RT completion and progresses over the years. The main manifestations of cutaneous and subcutaneous RIF are skin induration and 
thickening. RIF severity is graded using the Common Terminology Criteria for Adverse Events (CTCAE) scale. As this rating scale may be subjective, other tools have been developed, such as ultrasonography (US) quantification using a high-frequency transducer. Changes in tissue echogenicity (mild, moderate and severe) are observed in function of RIF severity (8). Older studies showed that measuring tissue deformation in response to an applied force assessed using an ultrasound probe is a quantitative method to monitor RIF, and correlates with symptoms and neck rotation restriction (9).

RIF is the results of a dysregulation of the wound-healing process and is characterized by trans-differentiation of fibroblasts into myofibroblasts and by excessive accumulation of extracellular matrix. Tissue injury, inflammation, and repair play a role in RIF development and progression. The first strategies to reduce or treat cutaneous and subcutaneous RIF were based on top-down approaches, such as the use of superoxide dismutase (SOD) (10) or of pentoxifylline combined with $\alpha$-tocopherol (vitamin E) $(11,12)$. A better understanding of RIF molecular mechanisms allowed defining potential therapeutic targets, such as transforming growth factor beta (TGF- $\beta$ ) that is activated by RT and is a fibrosis driver (13). Galunisertib, a TGF- $\beta$ receptor type I kinase inhibitor, combined with a platelet-derived growth factor receptor inhibitor significantly decreased lung RIF in mice models (14). The safety of an antiTGF- $\beta$ antibody (GC1008) is currently assessed in early clinical trials in patients with idiopathic pulmonary fibrosis (NCT00125385). Besides TGF- $\beta$ targeting, we and others reported that the Rho/ROCK/CTGF signaling pathway also is involved in RIF development and maintenance $(15,16)$. Pharmacological modulation of this pathway using statins (i.e., HMG-CoA reductase inhibitors) limits and reduces RIF in vitro, ex vivo and in vivo in various preclinical models of normal tissue radiation-induced toxicity (17-20). 
Based on these promising preclinical results, we designed a biology-driven phase II clinical trial to assess pravastatin efficacy in patients with delayed cutaneous and subcutaneous grade $\geq 2$ RIF after HNSCC RT (NCT xxx).

\section{METHODS}

The protocol was approved by all local institutional review boards and was accepted by the ethics committee of $\mathrm{xxx}$ (file number 10-001).

\section{Patients}

This bicentric phase II clinical trial enrolled 61 patients with cutaneous and subcutaneous RIF (grade $\geq 2$, NCI-CTCAE v4.0) diagnosed at least 6 months but less than 24 months after HNSCC treatment (i.e., adjuvant or exclusive RT, combined or not with concomitant chemotherapy). Patients were in complete remission at inclusion.

Additional inclusion criteria were adequate kidney function (serum creatinine $\leq 130 \mu \mathrm{M} / \mathrm{L}$ ) and hepatic function (aspartate aminotransferase and alanine aminotransferase levels at least 2 times lower than the laboratory upper normal limit; bilirubin level 1.5 times lower or more than the laboratory upper normal limit).

Exclusion criteria were long-term steroid therapy, or current treatment with statins, fibrates or cyclosporine; history of severe heart failure; history of muscle toxicity during previous treatments with fibrates or statins; history of hereditary muscle diseases; and baseline muscle creatine kinase (MM-CK) levels 3 times higher than the laboratory upper normal limit. 
At baseline, all patients underwent head and neck computed tomography (CT) to confirm HNSCC remission and high-frequency US (HF-US; at least 16-MHz linear transducer) to assess RIF thickness (in mm) compared with neighboring normal skin (upper part of the chest wall). The radiologists who performed the HF-US assessments (image collection and interpretation) were HF-US experts. As RIF is a dynamic process due to permanent extracellular matrix remodeling, RIF thickness was measured at its thickest point at baseline and at all the study time points.

Before inclusion, a written informed consent was obtained from all patients. Then, investigators from the two centers sent by fax the data required for the patient's registration to the xxx. After eligibility check and registration, a unique identification number was assigned to each patient and provided by fax to the investigator and to the pharmacist. Thus, patient registration was done independently from the study investigators. Pravastatin was given to the patients by the hospital pharmacist only after registration.

\section{$\underline{\text { Treatment }}$}

Treatment (40 mg pravastatin/day per os for 12 months) began at inclusion. Dose adjustment was not permitted. Premature drug discontinuation was planned in the case of pravastatin-related toxicity (renal, hepatic or muscle problems), cancer progression, consent withdrawal, or major protocol violation. Patients who discontinued pravastatin were followed like all the other patients enrolled in the trial. Neck motion exercises or scar manipulation were not performed during the study because at that time they were not part of the standard of care for HNSCC in $\mathrm{xxx}$.

\section{$\underline{\text { Endpoints }}$}

The primary endpoint was RIF thickness reduction of at least 30\% (compared with baseline) measured by cutaneous HF-US at 12 months. 
The secondary efficacy endpoints were reduction of RIF severity (according to the CTCAE v.4.0) evaluated by clinical examination, and QoL changes using the selfadministered VQ-Dermato questionnaire (21). The VQ-Dermato questionnaire is a valid and reliable dermatology-specific QoL instrument for chronic skin diseases, particularly for assessing the effect on QoL of therapeutic strategies (21). It includes seven dimensions (selfperception, daily living activity, mood state, social functioning, leisure activity, treatmentinduced limitations, and physical discomfort) explored by 28 items.

Pravastatin tolerance and compliance were evaluated. Pravastatin-related toxicities were assessed by clinical examination and by blood testing (cholesterol and MM-CK level variations).

\section{Follow-up}

Follow-up visits with the investigator were planned each month during the first three months and then at 6,12, 18 and 24 months after inclusion. RIF was evaluated clinically and by HF-US every 6 months after treatment start. Patients were asked to fill in the VQ-Dermato questionnaire at baseline and at 6, 12, 18 and 24 months after treatment start. Pravastatinrelated toxicities were assessed monthly during the first 3 months, and then at 6 and 12 months.

\section{$\underline{\text { Ancillary study }}$}

Before enrollment, an ancillary study to assess pravastatin biological efficacy was proposed to each patient. After signature of the written informed consent for the ancillary study, a skin punch biopsy in the RIF area was carried out before pravastatin treatment initiation and at 12 months. Biopsies were processed using classical histopathological procedure. Hematoxylin-Eosin (HE) staining was used for histological analysis and Sirius 
Red staining for quantification of collagen infiltration, as previously described (22). Each patient was its own control.

\section{STATISTICAL ANALYSIS}

This single-stage phase II trial tested the null hypothesis that the success rate would be lower than $10 \%$ versus the alternative hypothesis that it would be higher than $30 \%$. This required the inclusion of 40 evaluable patients (i.e., patients who received pravastatin for at least 11 months). If there were more than eight successes among the 40 evaluable patients, pravastatin would be considered interesting in this setting. With this design, the one-sided alpha error rate was $4.2 \%$ and the power was $94.5 \%$. According to the expected rate of early discontinuation (30\%), around 55 patients were needed for the trial.

The success rate (according to the HF-US assessment and CTCAE grading) was described with the 95\% confidence interval. The paired t-test was used to compare the VQ-Dermato scores at baseline and at 12 months, and to compare RIF thickness and normal skin thickness at baseline. As the sample size was small, the Wilcoxon signed rank test was used when appropriate and gave similar results as the paired t-test.

This study was registered at ClinicalTrials.gov, number xxx.

\section{ROLE OF THE FUNDING SOURCE}

The study funder $(\mathrm{xxx})$ had no role in the study design, in the data collection, analysis and interpretation, or in the report writing. The corresponding author had full access to all data and the final responsibility for the decision to submit for publication. 


\section{$\underline{\text { RESULTS }}$}

\section{Pravastatin is well tolerated and shows anti-fibrotic effect in a subset of patients}

From February 2011 to April 2016, 61 patients with grade $\geq 2$ cutaneous and subcutaneous RIF after HNSCC were registered (Figure 1). One patient was not eligible because he was already treated with statins, and was excluded from the analyses. The patients' demographic and clinical characteristics at baseline are listed in Supplementary table 1. The total RT dose ranged from 50 to $70 \mathrm{~Gy}$. Patients were mainly treated by 3D-conformal RT (61\%), and the others by IMRT (37\%). At baseline, $62 \%$ of patients had grade 2 RIF and $37 \%$ grade 3 RIF (Table 1). RIF was detected after a mean of 9.9 months post-RT. At baseline, skin thickness (measured by HF-US) was significantly increased in the RIF area compared with normal tissue (3.44 mm versus $1.97 \mathrm{~mm}$; $\mathrm{p}=0.0004)$.

Eighteen patients stopped pravastatin before 11 months of treatment because of grade $\geq 2$ pravastatin-related toxicities $(n=8)$, consent withdrawal or patient refusal to continue treatment $(n=5)$, or tumor relapse or death $(n=5)$. Among the patients with pravastatin-related toxicities, six stopped treatment during the first 3 months after initiation because of: grade 2-3 myalgia ( $\mathrm{n}=3$; pravastatin treatment duration: $0.3-3$ months), grade 3 arthralgia $(n=1$; pravastatin treatment duration: 3 months), grade 3 abdominal pain ( $n=1$; pravastatin treatment duration: 2.8 months), and grade 3 esophagitis $(\mathrm{n}=1$; pravastatin treatment duration: 1.7 months). These toxicities led to the definitive discontinuation of pravastatin. The other two patients reported hypersensitivity reaction ( $\mathrm{n}=1$ after 6 months of pravastatin treatment), and grade 1 diarrhea and grade 1 erectile dysfunction $(n=1$ after 8.7 months of pravastatin treatment). In total, 42 patients took pravastatin for at least 11.6 months. Among them, 40 patients underwent HF-US assessment both at baseline and at 12 months. In these 40 patients, the mean RIF thickness was $4.04 \mathrm{~mm}$ at baseline and $2.24 \mathrm{~mm}$ at 12 months (reduction by 
$16.9 \% \pm 38.8 \%$ ) (Figure 2). A RIF thickness decrease of $30 \%$ or more was observed in 15 patients (Table 1), corresponding to a success rate of $35.7 \%$ (95\% confidence interval: $21.6 \%$ $-52.0 \%)$. Therefore, according to the hypotheses tested in this trial, the use of pravastatin as anti-fibrotic agent was successful. Besides RIF thickness decrease, pravastatin also reduced RIF severity $(\mathrm{CTCAE})$ in $50 \%$ of patients $(95 \%$ confidence interval $=34.2 \% ; 65.8 \%)$. In eight patients, RIF thickness and severity were decreased at the 12-month follow-up visit. After pravastatin completion, no "rebound effect" was observed. RIF thickness, assessed by HF-US, was not significantly different at 12 months (mean=2.24 ( $\mathrm{SD}=1.07)$; median=2.05 [range=1.00;7.60]), 18 months $($ mean=2.47 $(\mathrm{SD}=2.28) ;$ median=1.9 $[$ range=1.10;15.0] $)$ and 24 months $($ mean=2.92 $(\mathrm{SD}=5.96) ;$ median $=1.7$ [range=1.20;36.0]).

Although the VQ-Dermato questionnaire was not always fully completed by the patients, analysis of the score variations between baseline and the 12-month follow-up indicated that pravastatin treatment significantly improved the self-perception $(p=0.027)$, mood state $(p=0.010)$, social functioning $(p=0.040)$ and global scores $(p=0.002)$ (Supplementary Table 2).

Among the patients who received pravastatin for more than 11 months, compliance was excellent with a mean treatment duration of 365 days [min, $\max =335-365]$ and the drug was well-tolerated (Table 2).

$\underline{\text { Skin structure is improved and collagen infiltration decreased after 12-month treatment }}$ with pravastatin (ancillary study)

HE staining of skin punch biopsies collected before and after pravastatin treatment ( $\mathrm{n}=19$ patients) showed that after 12 months of treatment, the skin histopathological structure was improved in 14 patients, as indicated by the decreased infiltration of immune cells and 
normalization of the epidermis thickness (Figure 3A). In the other five patients, no modification was observed. Moreover, collagen infiltration (Sirius Red staining quantification) was decreased in 8/14 patients after pravastatin treatment (Figure 3B and C).

\section{DISCUSSION}

This phase II clinical trial confirmed previous preclinical data on pravastatin antifibrotic potential. To the best of our knowledge, this is the first study combining objective and subjective criteria (RIF thickness and severity, respectively) to provide evidence of pravastatin anti-fibrotic efficacy in patients. Although IMRT has significantly reduced the incidence of acute and late toxicities, grade $\geq 2$ RIF still occurs and pravastatin could be proposed to such patients. Pravastatin was well-tolerated and only six patients (10\%) experienced discomfort (arthralgia, myalgia) that led to treatment withdrawal during the first 3 months of the trial. This suggests that pravastatin could be better tolerated than the current anti-fibrotic treatment based on pentoxifylline/vitamin E that caused discomfort (hot flushes, nausea, epigastralgia, severe asthenia, headache, or vertigo) in $45 \%$ of patients (11), and definitive treatment discontinuation in $11 \%$ of patients $(n=3 / 27)$ because of myalgia, diarrhea or nausea during the first 4 months of treatment (23).

Tissue injury induced by RT can be managed by administering prophylactic agents (or radioprotectors) before RT or mitigators after RT completion, and by curative interventions, after the appearance of radiation-induced toxicities. Here, pravastatin was assessed as a curative approach (i.e., several months after RT completion and in the presence of established $\geq$ grade 2 fibrosis). This strategy presents several advantages, including the absence of interference with the anti-cancer treatments and its administration only to the patients who really need it. Curative treatment after RIF appearance are based on the idea that fibrotic tissue can be mobilized and the fibrogenic process reversed by normalizing tissue 
homeostasis. The biological basis of fibrosis reversion has been reviewed elsewhere (24-26), and several pharmacological strategies have been proposed to achieve this (reviewed by (26)).

As the objective evaluation of fibrosis regression is a critical issue in clinical trials, we chose HF-US to assess pravastatin efficacy and to obtain quantitative measurement of RIF thickness. Delanian and colleagues measured the variation in length and width of the cutaneous fibrotic surface to monitor the efficacy of the pentoxifylline-vitamin E combination (12). However, this measure is operator-dependent and consists in the palpation of the fibrotic block edges. Recently, a systematic review by Shaw and colleagues on objective tools including CT (densitometry and perfusion), Cutometer and US found that US is a better objective measurement than palpation (9). Moreover, $84.9 \%$ agreement of inter-rater reliability regarding RIF grade was reported when physical examination was associated with US (8); however, the value of US-based assessment of RIF modulation after anti-fibrotic treatment has never been evaluated. In our study, the decrease of both RIF thickness and severity was observed only in 8 patients. Our findings in normal tissue and RIF areas are in agreement with those of a pilot-study using HF-US for RIF assessment presented at the ESTRO 35 meeting (27). Nevertheless, additional investigations are needed to confirm HFUS value for RIF assessment during anti-fibrotic treatment.

One of the major secondary outcomes of the present phase II clinical trial is that pravastatin efficiently reduced RIF severity and improved QoL. Specifically, 50\% of patients displayed a RIF severity decrease of at least one point in the CTCAE grading system, resulting in a quality of life improvement, particularly self-perception, mood and social functioning. No other clinical trial assessing anti-fibrotic agents has focused on these secondary endpoints. Here, we found that pravastatin significantly improved three dimensions of the VQ-Dermato questionnaire (self-perception, mood state and social functioning) and consequently also the global score. Conversely, Gothard and colleagues did not observe any 
QoL improvement after 6 months of pentoxifylline- vitamin E treatment for breast RIF (28). Our results are consistent with those reported by Delanian and colleagues (pentoxifyllinevitamin $\mathrm{E}$ for at least 6 months), with a mean decrease of the SOMA score by $35 \%( \pm 20 \%)$ and by $48 \%( \pm 21 \%)$ at 6 months and 1 year, respectively (29).

Many preclinical studies assessed different anti-fibrotic agents that target TGF- $\beta$, inhibit collagen production, or deplete macrophages. Some clinical trials and pilot studies showed RIF reduction after low-dose interferon-gamma therapy $(n=4)(30)$, and higher range of motion after treatment with pirfenidone $(n=6)$ (31). Ongoing clinical trials are assessing different curative strategies: the Tocovid SupraBio-pentoxifylline combination in bowel radiation-induced disease after pelvic RT (NCT02230800); topical superoxide dismutase in skin RIF in patients after HNCC (NCT01771991). A phase I trial evaluates the efficacy of umbilical cord mesenchymal stem cells in established lung fibrosis (NCT02277145). Other clinical trials are assessing mitigation strategies, particularly for the prevention of lung fibrosis by administration of enalapril (NCT01754909), captopril (NCT00077064), or nicorandil (NCT02809456). To date, none of them has reported results comparable with those obtained here using a compound selected on the basis of its biological efficacy $(18,20,32)$. Finally, the results of our ancillary study are consistent with the clinical data, although performed in a limited number of patients. They showed that pravastatin treatment induced structural improvement of the skin in 14 of the 19 patients, suggesting that increasing the treatment duration could lead to further improvement. Moreover, collagen infiltration was reduced in $8 / 14$ patients. In these eight patients, RIF thickness also was reduced by more than $30 \%$ (by HF-US), or RIF severity grade was decreased. A specific evaluation of the Rho/ROCK/CTGF pathway would have been interesting, but was difficult to perform in skin punch biopsies due to their small size. These molecular analyses are more accurate in 
preclinical and experimental models in which more mechanistic studies can be conducted using both pharmacologic and genetic approaches.

In conclusion, this biology-driven phase II clinical trial shows a curative efficacy and good tolerance of pravastatin in patients with established cutaneous and subcutaneous grade $\geq 2$ RIF in the neck after RT for HNSCC. These results need to be confirmed in a phase 3 randomized trial. However, as very few anti-fibrotic strategies can be proposed to patients in the clinical practice, statins could be already used as secondary treatment in patients with severe cutaneous RIF. More studies are required to investigate the biological differences between responders and non-responders to better target the patients who will benefit from this strategy. 


\section{REFERENCES}

1. Fitzmaurice C, Allen C, Barber RM, et al. Global, regional, and national cancer incidence, mortality, years of life lost, years lived with disability, and disability-adjusted life-years for 32 cancer groups, 1990 to 2015: A systematic analysis for the global burden of disease study. JAMA oncology 2017;3:524-548.

2. Blanchard $P$, Baujat $B$, Holostenco $V$, et al. Meta-analysis of chemotherapy in head and neck cancer (mach-nc): A comprehensive analysis by tumour site. Radiother Oncol 2011;100:33-40.

3. Ang KK, Harris J, Wheeler R, et al. Human papillomavirus and survival of patients with oropharyngeal cancer. The New England journal of medicine 2010;363:24-35.

4. Hirota S, Tsujino K, Oshitani T, et al. Subcutaneous fibrosis after whole neck irradiation. Int J Radiat Oncol Biol Phys 2002;52:937-43.

5. Veldeman L, Madani I, Hulstaert F, et al. Evidence behind use of intensity-modulated radiotherapy: A systematic review of comparative clinical studies. The lancet oncology 2008;9:367-75.

6. Nevens D, Duprez F, Daisne JF, et al. Radiotherapy induced dermatitis is a strong predictor for late fibrosis in head and neck cancer. The development of a predictive model for late fibrosis. Radiotherapy and oncology : journal of the European Society for Therapeutic Radiology and Oncology 2017;122:212-216.

7. Shaw SM, Skoretz SA, O'Sullivan B, et al. Valid and reliable techniques for measuring fibrosis in patients with head and neck cancer postradiotherapy: A systematic review. Head \& neck 2016;38 Suppl 1:E2322-34.

8. Deng J, Dietrich MS, Ridner SH, et al. Preliminary evaluation of reliability and validity of head and neck external lymphedema and fibrosis assessment criteria. European journal of oncology nursing : the official journal of European Oncology Nursing Society 2016;22:63-70.

9. Leung $\mathrm{SF}$, Zheng $\mathrm{Y}$, Choi $\mathrm{CY}$, et al. Quantitative measurement of post-irradiation neck fibrosis based on the young modulus: Description of a new method and clinical results. Cancer 2002;95:656-62.

10. Baillet F, Housset M, Michelson AM, et al. Treatment of radiofibrosis with liposomal superoxide dismutase. Preliminary results of 50 cases. Free radical research communications 1986;1:38794.

11. Delanian S, Porcher R, Balla-Mekias S, et al. Randomized, placebo-controlled trial of combined pentoxifylline and tocopherol for regression of superficial radiation-induced fibrosis. Journal of clinical oncology : official journal of the American Society of Clinical Oncology 2003;21:2545-50.

12. Delanian S, Porcher R, Rudant J, et al. Kinetics of response to long-term treatment combining pentoxifylline and tocopherol in patients with superficial radiation-induced fibrosis. Journal of clinical oncology : official journal of the American Society of Clinical Oncology 2005;23:8570-9.

13. Citrin DE, Prasanna PGS, Walker AJ, et al. Radiation-induced fibrosis: Mechanisms and opportunities to mitigate. Report of an nci workshop, september 19, 2016. Radiation research 2017;188:1-20.

14. Dadrich $\mathrm{M}$, Nicolay $\mathrm{NH}$, Flechsig $\mathrm{P}$, et al. Combined inhibition of tgfbeta and pdgf signaling attenuates radiation-induced pulmonary fibrosis. Oncoimmunology 2016;5:e1123366.

15. $x x x$.

16. $x x x$.

17. $x x x$.

18. xxx.

19. $x x x$.

20. $x x x$. 
21. Grob JJ, Auquier P, Martin S, et al. Development and validation of a quality of life measurement for chronic skin disorders in french: Vq-dermato. The reseaudepidemiolo gie en dermatologie. Dermatology (Basel, Switzerland) 1999;199:213-22.

22. xxx.

23. Gothard L, Cornes P, Brooker S, et al. Phase ii study of vitamin e and pentoxifylline in patients with late side effects of pelvic radiotherapy. Radiotherapy and oncology : journal of the European Society for Therapeutic Radiology and Oncology 2005;75:334-41.

24. Bentzen SM. Preventing or reducing late side effects of radiation therapy: Radiobiology meets molecular pathology. Nature reviews Cancer 2006;6:702-13.

25. Yarnold J, Brotons MC. Pathogenetic mechanisms in radiation fibrosis. Radiotherapy and oncology : journal of the European Society for Therapeutic Radiology and Oncology 2010;97:149-61.

26. Montay-Gruel P, Meziani L, Yakkala C, et al. Expanding the therapeutic index of radiation therapy by normal tissue protection. Br J Radiol 2018:20180008.

27. Schack LM, Overgaard J, Offersen BV, et al. Ep-1155: Radiation-induced morbidity evaluated by high-frequency ultrasound: A pilot study. Radiotherapy and oncology : journal of the European Society for Therapeutic Radiology and Oncology 2016;119:S551-S552.

28. Gothard L, Cornes P, Earl J, et al. Double-blind placebo-controlled randomised trial of vitamin e and pentoxifylline in patients with chronic arm lymphoedema and fibrosis after surgery and radiotherapy for breast cancer. Radiotherapy and oncology : journal of the European Society for Therapeutic Radiology and Oncology 2004;73:133-9.

29. Delanian S, Balla-Mekias S, Lefaix JL. Striking regression of chronic radiotherapy damage in a clinical trial of combined pentoxifylline and tocopherol. Journal of clinical oncology : official journal of the American Society of Clinical Oncology 1999;17:3283-90.

30. Gottlober $P$, Steinert $M$, Bahren $W$, et al. Interferon-gamma in 5 patients with cutaneous radiation syndrome after radiation therapy. Int J Radiat Oncol Biol Phys 2001;50:159-66.

31. Simone NL, Soule BP, Gerber L, et al. Oral pirfenidone in patients with chronic fibrosis resulting from radiotherapy: A pilot study. Radiat Oncol 2007;2:19.

32. Wang $Q$, Yang $X, X u Y$, et al. Rhoa/rho-kinase triggers epithelial-mesenchymal transition in mesothelial cells and contributes to the pathogenesis of dialysis-related peritoneal fibrosis. Oncotarget 2018;9:14397-14412. 


\section{FIGURES LEGENDS}

Figure 1. Study flow chart

Figure 2: Relative change in RIF thickness between baseline and 12 months of pravastatin treatment. Negative values indicate a reduction in RIF thickness between baseline and the 12month follow-up visit; positive values indicate an increase in RIF thickness between these time-points. In the y axis change into: Relative change (\%) in RIF thickness between baseline and 12 months.

Figure 3: Histological analysis of a skin punch biopsy from a patient with RIF who responded to pravastatin treatment. Punch skin biopsies in the RIF area were performed before pravastatin initiation and at 12 months. (A) Representative images of HE-stained skin sections before (left) and at 12 months of pravastatin treatment (right) showing decreased immune cell infiltration (asterisks) and normalization of the epidermis thickness (arrow); magnification X40. (B) Representative images of Sirius Red-stained sections before and at 12 months of pravastatin treatment showing the reduction of collagen deposition; magnification $\mathrm{X} 40$. (C) Densitometric analysis of collagen deposition before treatment and at 12 months of pravastatin treatment. 


\section{Figure 1}

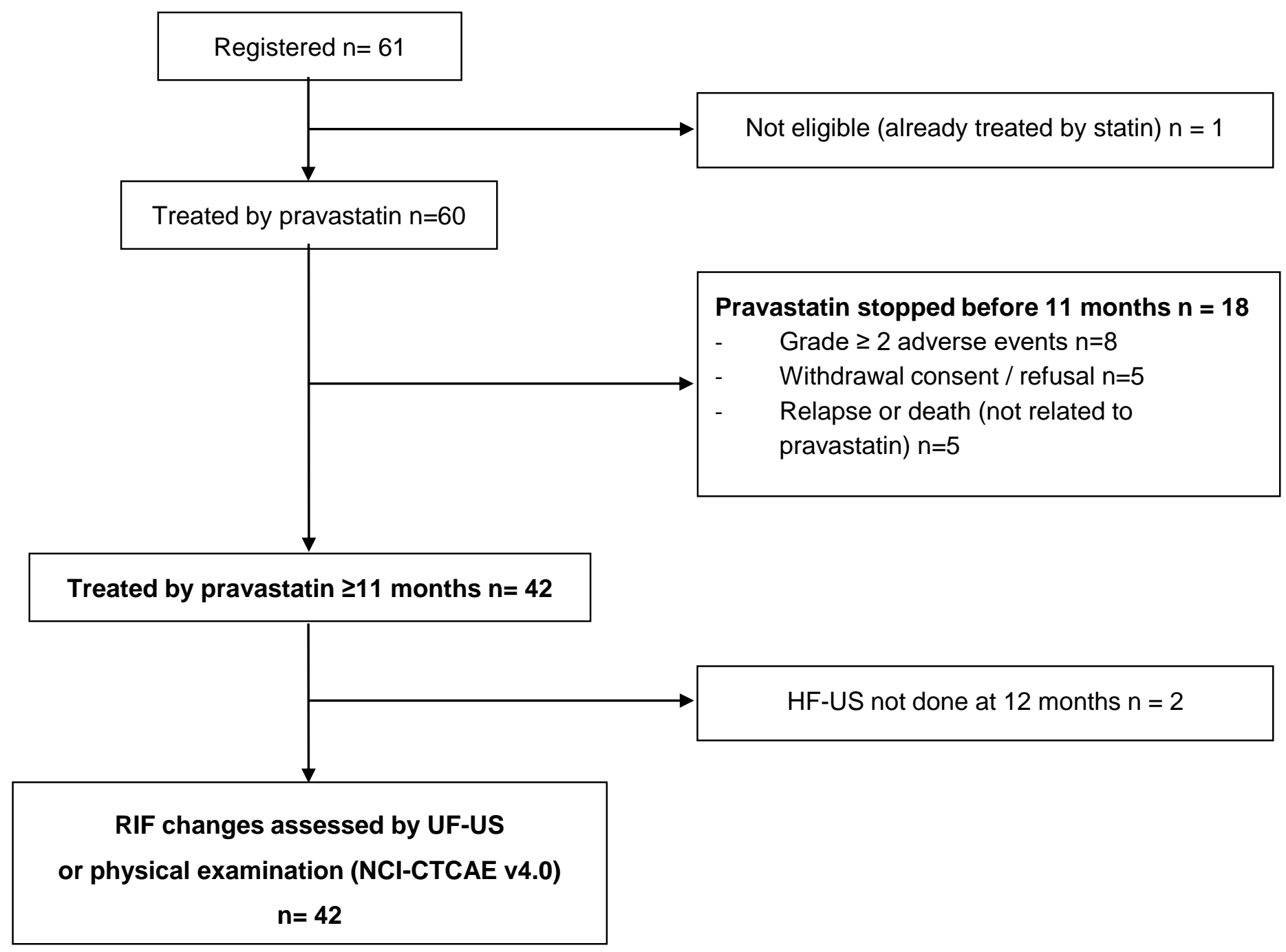




\section{Figure 2}

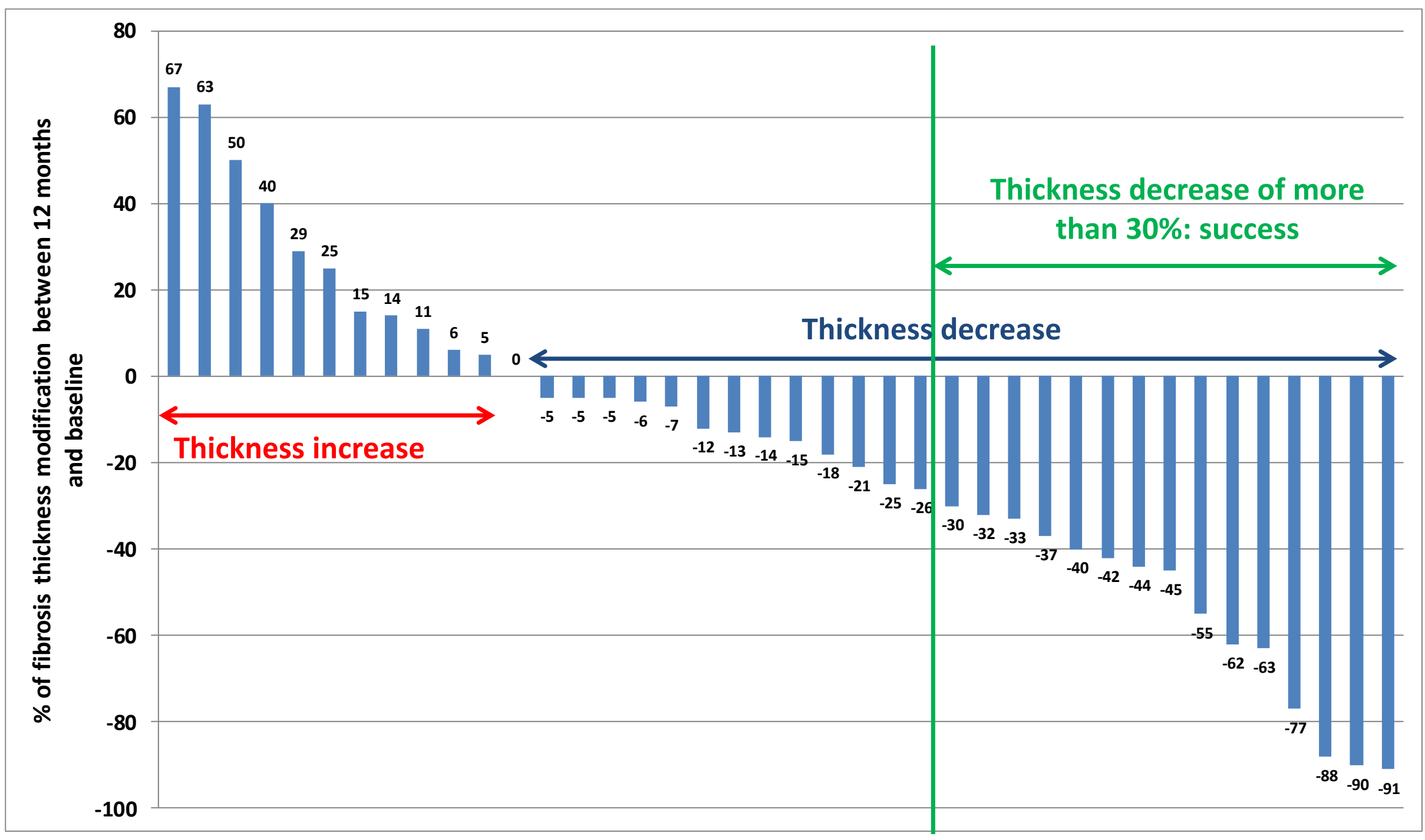




\section{Figure 3}

A

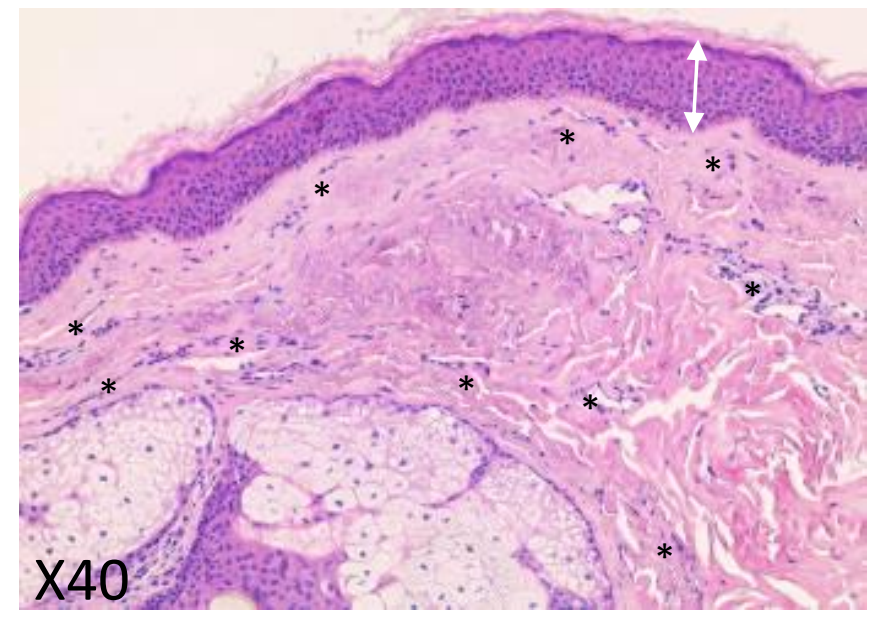

B

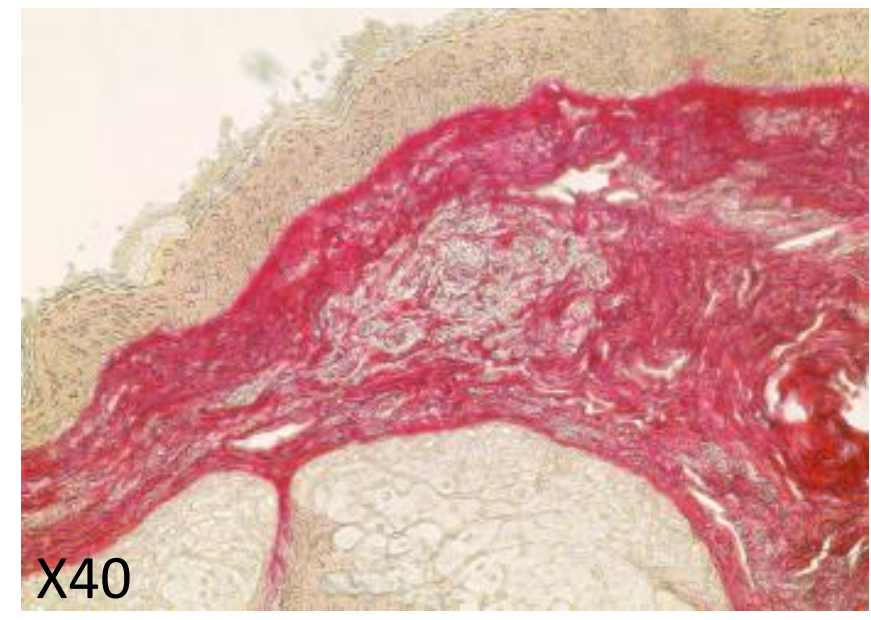

After 12 mo of Pravastatin treatment
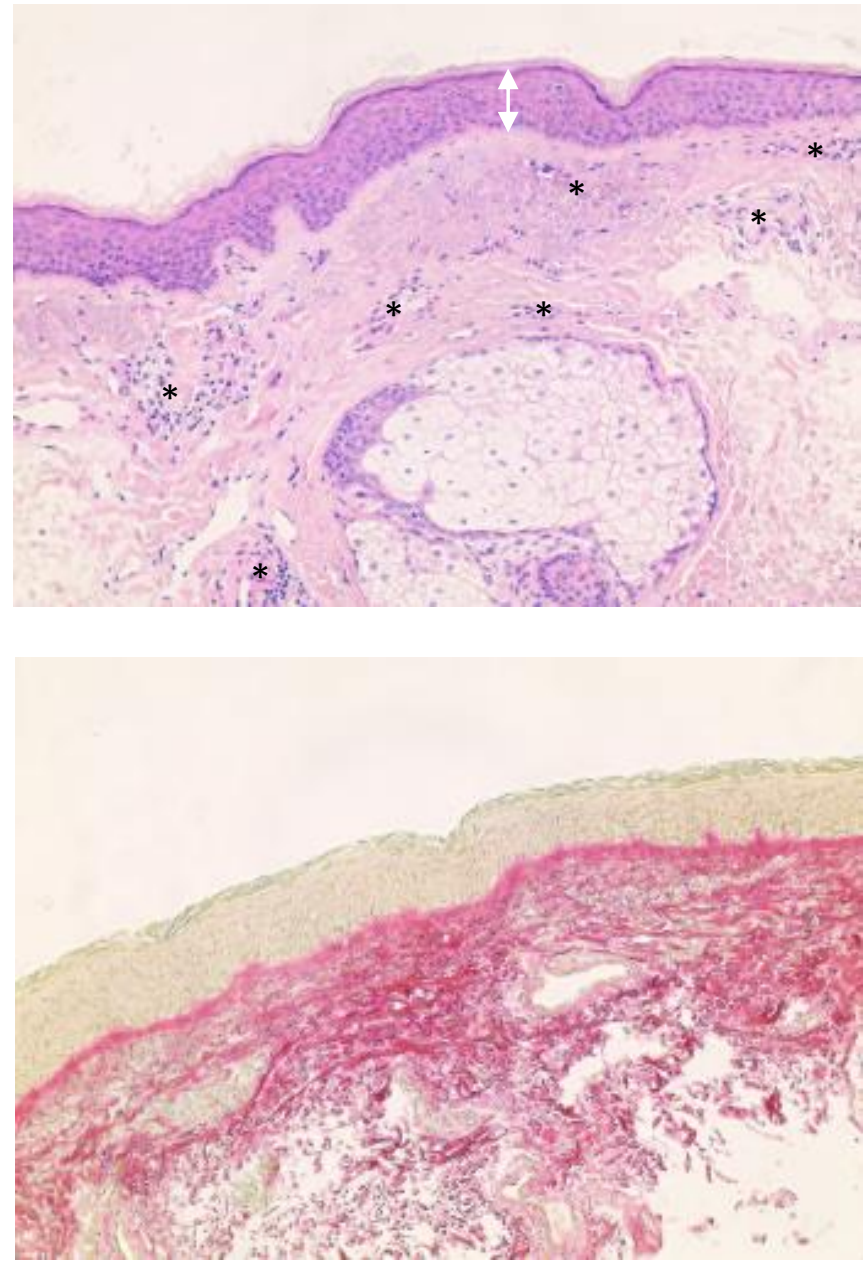

C

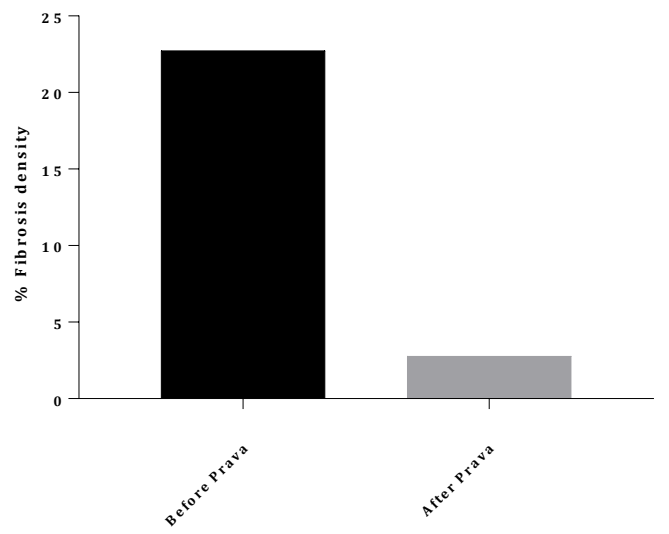


Table 1: Evaluation of fibrosis at baseline

\begin{tabular}{|c|c|c|c|}
\hline & $\begin{array}{l}\text { Pravastatin for } \\
<11 \text { months ( } \mathrm{N}=18)\end{array}$ & $\begin{array}{c}\text { Pravastatin for } \geq 11 \\
\text { months ( } N=42 \text { ) }\end{array}$ & $\begin{array}{l}\text { Total } \\
\mathrm{N}=60\end{array}$ \\
\hline \multicolumn{4}{|c|}{ TIMING OF RIF APPEARANCE (after RT completion, in months) } \\
\hline Mean (SD)] & $10.7(8.5)$ & $9.6(9.8)$ & $9.9(9.4)$ \\
\hline \multicolumn{4}{|c|}{ TIMING OF PRAVASTATIN INITIATION AFTER RIF ONSET (in months) } \\
\hline Mean (SD) & $17.7(14.1)$ & $16.9(10.5)]$ & $17.1(11.6)$ \\
\hline \multicolumn{4}{|c|}{ BASELINE RIF SEVERITY GRADE (clinical assessment according to the CTCAE v.4.0) } \\
\hline 2 & $11(61 \%)$ & $26(62 \%)$ & $37(62 \%)$ \\
\hline 3 & $7(39 \%)$ & $15(36 \%)$ & $22(37 \%)$ \\
\hline 4 & 0 & $1(2 \%)$ & $1(2 \%)$ \\
\hline \multicolumn{4}{|c|}{ BASELINE RIF AND HEALTHY SKIN THICKNESS (in mm, by HF-US) } \\
\hline RIF thickness (Mean (SD); & $2.30(0.96)$ & $3.92(4.42)$ & $3.44(3.80)$ \\
\hline median [range]) & $2.45[0.70-4.40]$ & $2.40[0.70-20]$ & $2.45[0.70-20]$ \\
\hline Healthy skin thickness (Mean (SD); & $1.47(0.52)^{*}$ & $2.17(3.53)^{*}$ & $1.97(2.99)^{* *}$ \\
\hline median [range]) & $1.60[0.40-2.40]$ & $1.60[0.70-24]$ & $1.60[0.40-24]$ \\
\hline $\begin{array}{l}\text { Thickness difference between RIF and } \\
\text { healthy skin (Mean (SD); } \\
\text { median [range]) }\end{array}$ & $\begin{array}{c}0.71(0.86)^{*} \\
0.70[-1.4 ; 2.0]\end{array}$ & $\begin{array}{c}1.38(2.78)^{*} \\
0.70[-4.0 ; 15.4]\end{array}$ & $\begin{array}{c}1.18(2.39)^{* *} \\
0.70[-4.0 ; 15.4]\end{array}$ \\
\hline \multicolumn{4}{|c|}{ PRIMARY ENDPOINT - RIF THICKNESS DECREASE (between baseline and the 12-month assessment) } \\
\hline $\begin{array}{l}\text { Success (i.e., thickness decrease of } 30 \% \\
\text { or more compared with baseline) [95\% } \\
\text { confidence interval] }\end{array}$ & $\begin{array}{c}0(0 \%) \\
{[0 \%-18.5 \%]}\end{array}$ & $\begin{array}{c}15(35.7 \%) \\
{[21.6 \%-52.0 \%]}\end{array}$ & - \\
\hline $\begin{array}{l}\text { Failure (i.e., thickness decrease lower } \\
\text { than } 30 \% \text { compared with baseline) }\end{array}$ & $4(22.2 \%)$ & $25(59.5 \%)$ & - \\
\hline
\end{tabular}




\begin{tabular}{|c|c|c|c|}
\hline Unknown - HF-US not done & $14(77.8 \%)$ & $2(4.8 \%)$ & - \\
\hline \multicolumn{4}{|c|}{$\begin{array}{l}\text { SECONDARY ENDPOINT - RIF CTCAE GRADING MODIFICATION (12-month assessment compared with } \\
\text { baseline) }\end{array}$} \\
\hline Decrease of severity (-2 points) & $0(0 \%)$ & $2(5 \%)$ & - \\
\hline Decrease of severity (-1 point) & $3(16.7 \%)$ & $19(45 \%)$ & - \\
\hline Stable (same score) & $5(27.8 \%)$ & $17(40 \%)$ & - \\
\hline Increase of severity (+1 point) & $0(0 \%)$ & $3(7 \%)$ & - \\
\hline No clinical evaluation at 12 months & $10(55.6 \%)$ & $1(2 \%)$ & - \\
\hline $\begin{array}{l}\text { Success (grade decrease) } \\
\text { [95\% confidence interval] }\end{array}$ & $\begin{array}{l}3 * *(16.7 \%) \\
{[3.6 \%-41.4 \%]}\end{array}$ & $\begin{array}{c}21(50.0 \%) \\
{[34.2 \%-65.8 \%]}\end{array}$ & - \\
\hline \multicolumn{4}{|c|}{ RIF AND HEALTHY SKIN THICKNESS AT 12 MONTHS (in mm, by HF-US) } \\
\hline $\begin{array}{l}\text { RIF thickness (Mean (SD); } \\
\text { median [range]) }\end{array}$ & & $\begin{array}{c}2.24(1.07) \\
2.05[1.00-7.60]\end{array}$ & \\
\hline $\begin{array}{l}\text { Healthy skin thickness (Mean (SD); } \\
\text { median [range]) }\end{array}$ & & $1.33(0.42) \$$ & \\
\hline
\end{tabular}

* data missing for one patient;

** data missing for two patients;

${ }^{* * *}$ two patients received pravastatin for 1.7 months and one patient for 8.7 months

\$ No significant difference in healthy skin thickness between baseline and 12 months 
Table 2: Pravastatin tolerance in the 42 patients who received pravastatin for more than 11 months

\begin{tabular}{|c|c|}
\hline ARTHRALGIA & $N(\%)$ \\
\hline None & $39(93 \%)$ \\
\hline Grade 1 & $1(2 \%)$ \\
\hline Grade 2 & $2(5 \%)$ \\
\hline \multicolumn{2}{|l|}{ MYALGIA } \\
\hline None & $32(76 \%)$ \\
\hline Grade 1 & $8(19 \%)$ \\
\hline Grade 2 & $1(2 \%)$ \\
\hline Grade 3 & $1(2 \%)$ \\
\hline \multicolumn{2}{|l|}{ CRAMPS } \\
\hline None & $34(81 \%)$ \\
\hline Grade 1 & $8(19 \%)$ \\
\hline \multicolumn{2}{|l|}{ FATIGUE } \\
\hline None & $39(93 \%)$ \\
\hline Grade 1 & $3(7 \%)$ \\
\hline \multicolumn{2}{|c|}{ DYSPHAGIA - ESOPHAGITIS } \\
\hline None & $39(93 \%)$ \\
\hline Grade 1 & $1(2 \%)$ \\
\hline Grade 2 & $2(5 \%)$ \\
\hline
\end{tabular}

